Mobilidades Territoriais e Textuais

송 


\title{
Habitar a diásporA \\ representaşōes do imaginário da distância em textos literários contemporâneos
}

\author{
HABITER LA DIASPORA: REPRÉSENTATIONS DE L'IMAGINAIRE \\ DE LA DISTANCE DANS DES TEXTES LITTÉRAIRES CONTEMPORAINS
}

Maria Bernadette Porto*

Universidade Federal Fluminense / CNPq

\begin{abstract}
RESU M O
A partir da leitura da representação do imaginário da distância em obras inspiradas pela perspectiva diaspórica da cultura, as reflexões desenvolvidas privilegiam as línguas e identidades em trânsito, a noção de habitabilidade e a consciência do exílio na contemporaneidade.
\end{abstract}

PALAVRAS-CHAVE

Diáspora, distância, habitar

\begin{abstract}
Nunca me acontece estar somente aqui como corpo fechado em si mesmo, ao contrário, estou lá, isto é, mantenho-me em todo o espaço; e é somente assim que posso percorrê-lo. ${ }^{1}$

Mesmo em Kyoto sinto saudades de Kyoto. ${ }^{2}$
\end{abstract}

As palavras de Heidegger, citadas como epígrafe, remetem ao pensamento do ensaísta canadense François Paré e, em particular, a seu conceito de distância habitada. Segundo ele, essa afirmação do filósofo alemão concilia o sujeito na habitabilidade da distância que se instaura "entre um aqui e um lá, esses dois polos pertencendo a uma mesma consciência em deslocamento". ${ }^{3}$

Cabe lembrar que a experiência da distância pode ser vivenciada no interior de um mesmo espaço, como se destaca nas citações escolhidas, que sugerem a necessidade de se relativizar a noção de lugar. Longe de serem considerados como fixos e permanentes, os lugares - que são móveis, provisórios e inacabados, constituindo-se como convite a

\footnotetext{
*mbvporto@hotmail.com

${ }^{1}$ HEIDEGGER. Essais et conférences, p. 187-188. Todas as traduções apresentadas são de nossa autoria.

${ }^{2}$ LISBOA. Rakushisha, p. 13.

${ }^{3}$ PARÉ. Postface: le fils éperdu, p. 187.
} 
possíveis partidas - apontam para a existência do alhures. Por mais familiares que possam parecer à primeira vista, insinuam a ideia da estrangeiridade. Por isso mesmo, é preciso repensar a noção de casa nos novos contextos diaspóricos de nossa época, como se depreende no belo poema intitulado "Morada", da escritora de origem cubana Aimée Bolaños:

\author{
mi nueva casa es un puente \\ sobre un río que pasa \\ cuando lo atravieso \\ me sé en verdadera morada \\ mi nueva casa es un camino \\ sobre una tierra alada \\ cuando ando celebro \\ cada uno de mis pasos ${ }^{4}$
}

Inserida no imaginário da distância, característico das produções nascidas na diáspora, a casa se reveste aqui dos atributos da mobilidade, traduzindo-se como ponte e como caminho. Prenhe de muitos significados, a ponte pode não só remeter ao entredois cultural, como aparece na poética da escritora canadense Gabrielle Roy e, em particular, na abertura de seu livro La détresse et l'enchantement, ${ }^{5}$ como pode também anunciar o gesto da partida em direção a um outro lugar. Aos olhos de François Paré, em seu rico ensaio Le fantasme d'Escanaba, o mesmo signo espacial,

dá luz à distância na qual um a um os migrantes se engajam, para formar, assim que a fronteira é ultrapassada, traçados diaspóricos, comunidades improváveis de estuários em movimento, que, como é sabido, darão origem, mais uma vez, a outras derivas e a outras comunidades frágeis. ${ }^{6}$

Mulher-traduzida, para evocarmos a célebre categoria de "homens traduzidos", ? proposta por Salman Rushdie para definir escritores da diáspora, a autora do poema "Morada" habita a movência, os movimentos do devir. Seu território, como é sugerido no próprio título da obra Las palabras viajeras, de onde foi extraído o poema "Morada", deve ser o das palavras andantes, ${ }^{8}$ uma vez que mora em trânsito nas searas da linguagem. Iluminados pela perspectiva diaspórica, os versos do poema em questão indicam que o importante não é a chegada, mas, sim, o próprio ato de se deslocar sem parar, de continuar a caminhada sem fim. Nesse sentido, a autora parece ilustrar considerações

\footnotetext{
${ }^{4}$ BOLAÑOS. Las palabras viajeras, p. 26.

${ }^{5}$ Trata-se de um texto de cunho autobiográfico no qual a narradora relata uma difícil experiência vivenciada por ela e sua mãe: a travessia habitual da ponte Provencher, que unia e separava dois mundos opostos, representados, respectivamente, pela cidade francófona de Saint-Boniface e por Winnipeg, capital da província anglófona do Manitoba. Para ela e sua mãe, tal percurso correspondia à passagem do familiar ao estrangeiro, do particular ao geral, da hospitalidade à hostilidade. O confronto entre duas línguas e duas culturas abriu, desde muito cedo, os olhos da autora para a questão do estrangeiro no Canadá.

${ }^{6}$ PARÉ. Le fantasme d'Escanaba, p. 114-115.

${ }^{7}$ RUSHDIE. Patries imaginaires: essais et critiques 1981/1991, p. 28.

${ }^{8} \mathrm{O}$ título da obra de Bolaños evoca Eduardo Galeano, autor do livro As palavras andantes.
} 
de Pierre Ouellet que, em seu livro L'esprit migrateur: essai sur le non-sens commun, afirma que a "experiência de passar, de atravessar espaços e tempos consideráveis suplantou largamente em nossa realidade geocultural, a ação de se instalar, de fundar, de se estabelecer". ${ }^{9}$

Outro ser da geografia da desterritorialização e representante da diáspora haitiana no Quebec, Joël Des Rosiers, contribui para a releitura da noção de casa/terra de origem: "O verdadeiro lugar do nascimento é aquele em que se tem, pela primeira vez, um olhar estrangeiro sobre si mesmo; minhas primeiras pátrias foram terras estrangeiras." ${ }^{10}$ Nas palavras do autor, verifica-se a necessidade de uma distância para se afirmar a sensação de pertencimento, o que corresponde a um olhar imbuído da perspectiva diaspórica.

"Ressemantizado na pluralidade de suas conotações viajantes, entendida a condição migrante e seu pensamento descentrado como consubstancial à alta modernidade", ${ }^{11}$ o conceito de diáspora se revela muito produtivo para o autor do livro La distance habitée (2003). Trazendo nova luz aos estudos das chamadas literaturas da exiguidade - título de outro ensaio de sua autoria publicado em 1992 -, François Paré mostra que as noções de resistência e de luta pela sobrevivência não dão conta da complexidade do que se passa em contextos minoritários e diaspóricos. ${ }^{12}$ Para tanto, o teórico canadense se vale dos conceitos de diáspora, de itinerância e de distância habitada que sugere a neutralização das oposições entre ausência e presença. Para ele, toda cultura - e, em especial, as culturas minoritárias - permite, a cada um de nós, habitar a distância que nos separa dos outros em um universo intersticial, ${ }^{13}$ marcado pela heterogeneidade e pela pluralidade de memórias. No centro da consciência diaspórica, Paré identifica a plurilocalidade, ligada a uma lógica plural da história e à fratura da memória coletiva. ${ }^{14}$

Para melhor desenvolvimento das reflexões centradas no imaginário da distância em contextos diaspóricos, serão aqui propostos dois momentos de análise. Em primeiro lugar, será mostrado como a consciência diaspórica se reflete na própria prática linguística referente ao processo criativo de escritores do mundo contemporâneo. Posteriormente, o breve estudo aqui proposto se orientará em direção à leitura de aspectos do romance La traversée du continent, de Michel Tremblay (2007), que coloca em circulação a representação da diáspora vivenciada, no plano ficcional, por uma família no interior do Canadá.

\footnotetext{
${ }^{9}$ OUELLET. L'esprit migrateur: essai sur le non sens commun, p. 123.

${ }^{10}$ DESROSIERS. Théories caraïbes: poétiques du déracinement, p. 75

${ }^{11}$ BOLAÑOS. Diáspora, p.167-168.

${ }^{12}$ Para um maior aprofundamento da leitura da obra La distance habitée, o capítulo de minha autoria, "Escritas do exílio: habitar e representar a distância", oferece outras pistas de análise para se abordar o pensamento de Paré. (cf. PORTO; VIANNA NETO. Habitar e representar a distância em textos literários canadenses e brasileiros, p. 15-34).

${ }^{13}$ PARÉ. La distance habitée, p. 62.

${ }^{14}$ PARÉ. La distance habitée, p. 72.
} 


\section{A VIVÊNCIA DA DISTÂNCIA E O IMAGINÁRIO DAS LÍNGUAS NO PROCESSO DE CRIAÇÃO}

Consideradas como primeiros lugares da itinerância ${ }^{15}$ em culturas diaspóricas, as línguas constituem espaços de deslocamentos de sentidos, de trânsitos identitários, de movências inacabadas, de memórias de outros sotaques, da circulação de palavras estrangeiras e referências culturais. Para ilustrar sua leitura, Paré recorre ao escritor africano Abdelkabir Khatibi que, em seu romance Amour bilingue, explora o imaginário diglóssico e a interpenetração de línguas. Valorizando o caráter hospitaleiro de um idioma, Khatibi acredita ser habitável o intervalo entre o eu e o Outro:

(...) há sempre em cada palavra, em cada nome, em cada nome e sobrenome e nome próprio o desenho de outras palavras, sua caligrafia hospitaleira. Em cada palavra: outras palavras; em cada língua: a morada de outras línguas. ${ }^{16}$

Encontram-se no universo de autores marcados pela pluralidade de pertencimentos inúmeras referências à prática linguística e à escolha da língua de criação. Através da ideia de "surconscience linguistique", Lise Gauvin ${ }^{17}$ mostra, em vários de seus ensaios, que os escritores francófonos são obrigados a pensar a língua, sobretudo porque vivem continuamente a coexistência nem sempre tranquila de idiomas e signos culturais. Inspirados pelo "imaginário das línguas", noção explorada por Édouard Glissant, ao exercerem sua atividade criativa, levam em conta a existência da pluralidade de línguas no mundo. ${ }^{18}$ Por isso, mesmo quando escrevem em sua língua materna, não podem se expressar de maneira monolingue, sendo-lhes facultado o poder de erguer a Torre de Babel em qualquer idioma. ${ }^{19}$

Nesse sentido, a coabitação das línguas em contato no universo de escritores da diáspora adquire especial relevância, constituindo-se como fonte de criação. Assim, no conjunto da obra de autores representativos das mobilidades culturais, as reflexões sobre a adoção da língua estrangeira estão sempre presentes, apontando para fricções, ficções e impasses. Representante maior do exílio, a escritora Nancy Huston, que há muitos anos deixou sua terra natal (a província anglófona de Alberta, no Canadá) para viver na França, soube tirar partido do entre-dois, conferindo-lhe um sentido promissor. Em muitos de seus ensaios, reflete sobre suas duas línguas de escrita - o inglês e o francês -, trazendo uma efetiva contribuição para o estudo dos vínculos entre o exílio e o imaginário das línguas. Ao invés de se considerar como bilingue, vê-se marcada por um duplo analfabetismo ${ }^{20} \mathrm{e}$ tira partido de sua situação peculiar, de uma dupla distância - em relação à língua materna, o inglês, da qual se exilou, e em relação à língua estrangeira, o francês.

Após muitos anos de distanciamento de sua língua materna, que coincidiu com o abandono de sua pátria, Nancy Huston assumiu um retorno ao mesmo idioma. Enriquecido

\footnotetext{
${ }^{15}$ PARÉ. La distance habitée, p. 95.

${ }^{16}$ Citado por PARÉ. La distance habitée, p. 105.

${ }^{17}$ GAUVIN. Langagement: l'écrivain et la langue au Québec.

${ }^{18}$ GLISSANT. Introduction à une poétique du divers, p. 112.

${ }^{19}$ GLISSANT. Poétique de la relation, p. 123.

${ }^{20}$ HUSTON; SEBBAR. Lettres parisiennes: autopsie de l'exil, p. 77.
} 
"por uma longa e amorosa prática de uma língua estrangeira" ${ }^{21}$ - o francês -, o inglês é falado por ela com imperfeições e com sotaque, o que se dá ainda no exercício do francês, língua estrangeira tornada familiar. Depois de muito tempo distante de seu idioma e de seu país de origem, ela embaralha as fronteiras entre o familiar e o estrangeiro no âmbito das línguas. Constatando que "as coisas mudam. Trocam de lugar em seu foro interior", admite que o "exótico se torna familiar (...) e vice-versa. A estrangeira se torna materna, e a materna, adotiva."22

Não coincidindo perfeitamente com nenhum idioma e com nenhuma identidade, ela se sente profundamente canadense na convivência de duas línguas que "não querem se reunir, se dar as mãos, falar entre si", reivindicando "toda a ambiguidade de sua situação". ${ }^{23}$ E é justamente nessa ambiguidade, nessa tensão entre dois idiomas, que ela encontra inspiração para seu processo criativo que supõe a distância e a aprendizagem da relativização.

Orientada pela leitura diaspórica do mundo, Huston chega a se indagar sobre uma hipótese: "E se eu dispusesse de uma terceira língua - o chinês, por exemplo? Isso implicaria um terceiro imaginário, um terceiro estilo, uma terceira maneira de sonhar?"24 Associando, pois, o exercício de uma língua estrangeira a uma outra visão de mundo ligada à prática da distância, a autora aposta na vivência do estranhamento e da alteridade como forma produtiva de conhecimento.

Interrogando-se sem cessar sobre suas incertezas linguísticas diante do idioma estrangeiro, escapa à pretensa segurança que se tem na língua materna. Ao se reconhecer como estrangeira em toda parte, a autora aceita se desorientar, "perdre le Nord", ${ }^{25}$ adotando uma percepção de si mesma, própria a muitos exilados que se sentem múltiplos, em contínua procura identitária.

$\mathrm{Na}$ obra de algumas autoras do exílio, a ideia de busca se revela como uma longa travessia, que pode ser lida no âmbito de uma geopoética, como se viu no poema de Aymée Bolaños, citado no início destas reflexões. Na produção quebequense contemporânea, o ensaio Quatre mille marches, da escritora de origem chinesa Ying Chen, ilustra a prática de uma caminhada sempre inacabada que mantém intacta a distância. No mesmo ensaio, a necessidade do distanciamento em relação à língua francesa se faz presente nas considerações feitas por Chen a respeito de seu processo criativo. Evocando o mito de Sísifo, a autora crê que o idioma estrangeiro constitui um desafio sempre renovado e um impulso - ainda que frustrado - em direção a algo inatingível que dá sentido à sua existência. Por isso mesmo, ao longo de sua infindável trajetória identitária, conhece a certeza de ter partido e de nunca ter chegado, ${ }^{26}$ o que confirma a instabilidade de seu lugar na linha do devir.

\footnotetext{
${ }^{21}$ HUSTON. Désirs et réalités: textes choisis 1978-1994, p. 260.

${ }^{22}$ HUSTON. Désirs et réalités: textes choisis 1978-1994, p. 268.

${ }^{23}$ HUSTON. Désirs et réalités: textes choisis 1978-1994, p. 261.

${ }^{24}$ HUSTON. Nord perdu; suivi de Douze France, p. 52.

${ }^{25}$ Não é ingênua a escolha do título Nord Perdu: segundo a autora, "perdre le nord" equivale a "to be all abroad', expressão que significa "estar completamente no estrangeiro" (HUSTON. Nord perdu; suivi de Douze France, p. 12).

${ }^{26}$ CHEN. Quatre mille marches, p. 35.
} 
Por sua vez, ao revisitar seu percurso entre Oriente e Ocidente, a escritora de origem argelina Leïla Sebbar afirma que, para chegar a assumir o "eu", precisou andar durante muito tempo, "falar e viver a distância real, próxima do imaginário", e ouvir, longe do país natal, a voz da língua de seu pai, "a língua estrangeira, a estrangeira íntima. ${ }^{27}$ Em seus textos - em particular em Je ne parle pas la langue de mon père (2003) e L'arabe comme chant secret (2007) -, revela que sua vinda à escritura só foi possível pelo fato de nunca ter aprendido o árabe. Para ela - que mesmo tendo vivido muitos anos na Argélia, foi educada em francês, língua materna de sua mãe francesa e língua escolhida pelo pai na sua prática pedagógica -, escrever só se revelou viável a partir da experiência da falta, da consciência da perda, da distância que sempre a separou da língua paterna, transformada em matéria de criação.

Em um livro centrado na ideia de hospitalidade oferecida pela língua francesa, no qual se mostra profundamente ligado à cultura da França, o escritor japonês Akira Mizubayashi se define pelo duplo estatuto de estrangeiro. Depois de várias passagens, distribuídas ao longo das páginas, nas quais deixa transparecer certa alienação identitária, acaba seu livro Une langue venue d'ailleurs (2011) com a marca da dualidade de pertencimentos. Afirmando "seu desejo ardente de sair de si mesmo" e de assumir "o movimento migratório do pensamento", ${ }^{28}$ empreende a errância entre dois idiomas, ${ }^{29}$ entre dois universos culturais:

o dia em que me apoderei da língua francesa, perdi o japonês para sempre na sua pureza original. Minha língua de origem perdeu seu estatuto de língua de origem. Aprendi a falar como um estrangeiro na minha própria língua. Minha errância entre as línguas começou... Logo, não sou nem japonês nem francês. Finalmente, não cesso de me tornar estrangeiro diante de mim mesmo nas duas línguas, indo e vindo de uma à outra, para me sentir sempre defasado, fora de lugar. Mas, justamente, é desse lugar afastado que tenho acesso à palavra; é desse lugar, ou melhor, desse não-lugar que expresso todo meu amor pelo francês, toda minha ligação com o japonês. Sou estrangeiro aqui e lá e continuo a sê-lo. ${ }^{30}$

\section{VIAGEM NOS TRILHOS DA DIÁSPORA: PRIMEIRAS PISTAS DE LEITURA dO ROMANCE LA traverséE dU CONTINENT, de Michel TRemblay}

Como foi anunciado, será conferido relevo a um romance de Michel Tremblay, construído a partir da viagem de trem empreendida em 1913 por uma menina de 10 anos que deixa, sozinha, a pequena cidade de Sainte-Maria-de-Saskatchewan, onde morava com seus avós e irmãs, para encontrar sua mãe, com quem não tinha contato há muito tempo, na estação ferroviária de Montreal. Muitos anos depois da publicação de La grosse femme d'à côté est enceinte, com ternura e sensibilidade, Tremblay retrata a infância da personagem central desse romance e, em especial, o ritual iniciático vivido

\footnotetext{
${ }^{27}$ SEBBAR. L'arabe comme un chant secret. Récit, p. 63.

${ }^{28}$ MIZUBAYASHI. Une langue venue d'ailleurs, p. 268.

${ }^{29}$ MIZUBAYASHI. Une langue venue d'ailleurs, p. 267.

${ }^{30}$ MIZUBAYASHI. Une langue venue d'ailleurs, p. 267-268.
} 
por ela, durante três dias e três noites no interior de trens. O título dessa obra, La traversée $d u$ continent, poderia sugerir, na esteira dos chamados romances de estrada mesmo se se trata aqui da estrada de ferro - a mobilidade como apropriação territorial do continente americano. Todavia, a movência é feita no interior do próprio Canadá, país de dimensão continental. Vivenciado sob a forma da incerteza - já que se ignoram, de imediato, as razões que levaram a mãe a chamar a filha para junto de si -, o trajeto feito pela personagem Rhéauna (Nana) inclui pausas em cidades onde pernoita na casa de familiares e contínuas descobertas de figuras femininas de sua família que a surpreendem de diferentes formas.

Primeiro volume dedicado à saga da diáspora ${ }^{31}$ da família Desrosiers, dispersa pelo território canadense, La traversée du continent, lançado em 2007, foi seguido de duas outras publicações que constituem sequências do referido romance: La traversée de la ville (2008); e La traversée des sentiments (2009). Mais recentemente, a publicação de Le passage obligé (2010) retomou a história da diáspora da mesma família.

No primeiro volume dessa saga familiar, a experiência dos limites se revela de diversos modos para a personagem: é a passagem da familiaridade para o estranhamento; do espaço rural ao urbano; do Oeste para o Leste; da indefinição identitária à afirmação de sua individualidade; da vivência da exiguidade à da diáspora.

No que concerne ao sentido do percurso, de Oeste para Leste, é preciso lembrar que, no contexto dos "romances de estrada" 32 quebequense, dá-se o inverso, já que, engajados nas promessas de uma nova vida, personagens se orientam em direção às províncias do Oeste. Como pensa François Paré, o povoamento do Oeste "constitui (...) uma enorme reserva semiótica na qual buscam ainda inspiração as sociedades atuais, como o prova o prestígio das noções de fronteira e de americanidade no Quebec e de outros lugares." 33 Para ele, em todas as culturas diaspóricas do continente americano se sobressai uma mitologia da busca do espaço. Segundo Jean Morency, ${ }^{34}$ no romance escolhido, à nostalgia da casa perdida no meio do nada se sobrepõem a descoberta de outras cidades (Regina, Winnipeg, Saint-Boniface, Toronto, Ottawa e Montreal) e o espetáculo dos Grandes Lagos, além da tomada de consciência dos laços que unem a menina a familiares dispersos no Canadá. Assim se dá a passagem do sentimento do exíguo à expansão diaspórica, que corresponde à abertura de limites para a pequena Nana, limites não apenas físicos, mas também os que contribuem para o alargamento de seu olhar para o mundo.

\footnotetext{
${ }^{31}$ É Méo, avô de Nana, que escolheu o termo diáspora para falar da dispersão de suas filhas: "A diáspora dos Desrosiers. É a única grande palavra que ele conhece. - ele a encontrou em um artigo de jornal que falava dos judeus e dos cajuns - ele recorre facilmente a ela para falar de sua família" (TREMBLAY. La traversée du continent, p. 24). Aqui, pode-se evocar outro personagem que assistiu à dispersão de seus filhos: é Majorique, do texto De quoi t'ennuies-tu, Eveline?", de Gabrielle Roy. Tendo-se exilado na Califórnia, depois das andanças de seus filhos pelo mundo, assiste ao retorno deles, ao lado de seus cônjuges estrangeiros, o que redundou na "pequena comunidade das nações", marcada pela experiência diaspórica.

${ }^{32}$ Trata-se dos "romans de la route", inspirados, em grande parte, na literatura estadunidense.

${ }^{33}$ PARÉ. La distance habitée, p. 83.

${ }^{34}$ MORENCY. Romanciers du Canada français, p. 160.
} 
A sugestão de exiguidade aparece logo na abertura do romance, através de uma geopoética que valoriza a imagem da casa $^{35}$ - família protetora, porto seguro na imensidão territorial. A essa representação da casa como cinturão inserido no meio da paisagem de prados intermináveis, acrescenta-se a descrição da cidadezinha situada na província anglófona, que evoca a própria situação de insularidade e de fragilidade do Quebec no interior de um "oceano" anglófono:

Maria é uma anomalia em Saskatchewan. Pequeno enclave francófono católico no meio de um mundo de anglófonos protestantes, perdida no meio de pradarias tão vastas que se acreditaria que elas não têm limites e esquecida de todos por causa mesmo de sua diferença, ela se fechou em si mesma e acabou acreditando que é um mundo completo, definido, regido por leis imutáveis distribuídas por um único homem, o pároco. ${ }^{36}$

Para sair de seu casulo protetor e aventurar-se nos trilhos do desconhecido, Nana precisou se engajar na aprendizagem da distância, que supõe a disponibilidade para aceitar, mesmo com sofrimento, as perdas e o desaparecimento progressivo de pontos de referência. É o que se manifesta em uma bela passagem do romance, na qual, sentada no banco de uma charrete que vai levá-la à estação de trem, a menina olha para trás e vê desaparecer, pouco a pouco, toda a paisagem afetiva de sua infância:

Rhéauna se virou no seu assento. Ela olha a casa que se afasta, adernando um pouco porque a charrete não é das mais estáveis. Após centenas de passos, a casa começa a se enterrar nas espigas de milho por causa do declive suave no qual a charrete mergulha. A escada desaparece primeiro, depois a varanda. Nunca mais ela passeará ali, ao anoitecer (...) Não ouvirá mais os risos ou os gritos de suas irmãs, as advertências tão pouco severas de seus avós. A ponta das espigas de milho esconde a parte inferior da porta, sobe, dissimula a maçaneta e a pequena janela quadrada, o vento parece fazer uma onda que embaralha agora toda a fachada da casa atrás de uma cortina viva de cereais. Sobra apenas o telhado que desaparece por sua vez, como se a casa acabasse de afundar para sempre no solo fértil da província de Saskatchewan. ${ }^{37}$

A aprendizagem da distância se traduz como uma espécie de desapego, que Michel de Certeau ${ }^{38}$ reconhece nas viagens de trem. Para ele, nesse tipo de locomoção, os verbos "ver" e "atravessar" são dois modos complementares de separação. Por um lado, segundo o historiador, o ato de ver cria a distância do espectador, ${ }^{39}$ expressa pela fórmula

\footnotetext{
${ }^{35}$ A casa é cercada por uma varanda, construída pelo avô para impedir que as netas se percam nos campos sem fim que se estendem em direção do horizonte e onde é fácil se perder, no fim do verão quando o milho é muito alto (TREMBLAY. La traversée du continent, p. 13).

${ }^{36}$ TREMBLAY. La traversée du continent, p. 40.

${ }^{37}$ TREMBLAY. La traversée du continent, p. 66.

${ }^{38}$ CERTEAU. A invenção do cotidiano: 1. artes de fazer, p. 195.

${ }^{39}$ Outra forma de distanciamento vivenciado nas viagens de trem se refere, segundo De Certeau, à separação criada entre a interioridade do viajante, narrador em potencial, e a exterioridade da paisagem (A invenção do cotidiano: 1. artes de fazer, p.195). Tal paralelismo se confirma no universo de Tremblay, pois a menina Rhéauna imagina que, mais tarde, teria muito a contar sobre a experiência de seu deslocamento. Como aparece no romance La grosse femme d'à côté est enceinte, já adulta, a mesma personagem é marcada pelo gosto da fabulação e pelo prazer da leitura que lhe proporciona outras viagens.
} 
Não tocarás: "Quanto mais vês, menos agarras - despojamento da mão para ampliar o percurso da vista." 40 Por outro, os trilhos apontam para a obrigação de passar, de seguir uma mesma linha: “(...) vai, segue em frente, este não é teu país, nem aquele tampouco - imperativo do desapego que obriga a pagar o preço de um abstrato domínio ocular do espaço, deixando todo lugar próprio, perdendo o pé." ${ }^{41}$

Para assumir o desprendimento de suas raízes - que nunca será uma verdadeira ruptura -, Rhéauna passa por uma espécie de ritual que lhe permite vencer o medo e os interditos, saindo da infância para encarar outra etapa de sua existência. Em um gesto de coragem, na véspera de sua viagem, sai durante a noite da casa de seus avós para se deitar, em plena escuridão, sobre o solo das plantações de milho, com o intuito de ouvir crescer as espigas. Ao fazer isso, entra em contato com a força telúrica de sua terra e com a simbologia de sua história, deixando-se impregnar pelos mistérios de sua origem. Antes de se deslocar no eixo da horizontalidade da estrada de ferro, promessa das redes rizomáticas e diaspóricas, mergulha na profundeza vertical de suas raízes. Propondo uma nova gênese para a província de Saskatchewan, o capítulo em questão se apresenta como uma cosmogonia que reabilita a figura do ameríndio e sua leitura do mundo nos primórdios da história canadense. Resgatando sua origem familiar, marcada pelo encontro de culturas (o pai de Nana era francês e se casou com uma ameríndia), a personagem se depara com nova gênese que elege a figura de um ameríndio como o primeiro homem, distanciando-se dos ensinamentos que lhe foram passados pela religião católica. No momento de se afastar de suas origens, ela reforça os vínculos com a terra, parecendo atualizar o pensamento de Sibony, para quem a origem - que pode sempre ser reinventada - nos é necessária, para que seja possível dela nos afastar. ${ }^{42}$ Isso porque na origem é possível buscar o impulso em direção a outros lugares. ${ }^{43}$

\section{CONSIDERAÇÕES FINAIS}

As considerações desenvolvidas aqui, em seus dois momentos, confirmam as ideias propostas por Stuart Hall, para quem a cultura "não é uma questão de ontologia, de ser, mas de se tornar", ${ }^{44}$ e a diáspora, ligada aos movimentos do devir e às mobilidades culturais, constitui uma questão conceitual e epistemológica. ${ }^{45}$.

Ao se privilegiar o imaginário da distância, em grande parte à luz de ensaios de François Paré, foram relativizadas as noções de casa, terra natal e língua materna, uma vez que hoje se coloca sob suspeita uma concepção fechada e estável da noção de lugar. Assim, confirmou-se a opinião de Chambers, citado por Stuart Hall ${ }^{46}$ em seu clássico

\footnotetext{
${ }^{40}$ CERTEAU. A invenção do cotidiano: 1. artes de fazer, p. 194.

${ }^{41}$ CERTEAU. A invenção do cotidiano: 1. artes de fazer, p. 194-195.

${ }^{42}$ SIBONY. Entre-deux: l'origine en partage, p. 31.

${ }^{43}$ SIBONY. Entre deux: l'origine en partage, p. 55.

${ }^{44}$ HALL. Da diáspora: identidades e mediações culturais, p. 44.

${ }^{45}$ HALl. Da diáspora: identidades e mediações culturais, p. 28.

${ }^{46}$ HALL. Da diáspora: identidades e mediações culturais, p. 27.
} 
estudo: "Estamos todos, hoje, de uma forma ou de outra, longe de casa, o que nos leva a questionar a segurança dos lugares identitários que pensávamos habitar."

Ao longo das reflexões foram também salientados os vínculos entre distância, consciência diaspórica e processo criativo. Inicialmente foi visto como escritores do exílio se afastam de sua língua materna para produzirem textos inspirados pela fricção de idiomas, memórias e culturas. Posteriormente, através de uma breve leitura do romance de Michel Tremblay, foi realçada a representação do imaginário da distância como janela - ainda que reduzida à forma da pequena janela de um trem - que, não só abre para a vastidão da subjetividade, como também descortina, enquanto linhas de fuga, as promessas do novo e a contemplação das paisagens plurais do mundo, com seus espaços habitados e seus lugares precários a serem descobertos e apropriados, mesmo que de modo provisório.

\title{
A
}

\begin{abstract}
RÉ S U MÉ
À partir de la lecture de la représentation de l'imaginaire de la distance dans des œuvres inspirées par la perspective diasporique de la culture, les réflexions proposées privilégient les langues et les identités en transit, la notion d'habitabilité et la conscience de l'exil dans la contemporanéité.
\end{abstract}

\section{MOTS-CLÉS}

Diaspora, distance, habiter

\section{REFERÊNCIAS}

BOLAÑOS, Aimée. Las palabras viajeras. Madrid: Editorial Betania, 2010.

BOLAÑOS, Aimée. Diáspora. In: BERND, Zilá (Org.). Dicionário das mobilidades culturais: percursos americanos. Porto Alegre: Literalis, 2010. p. 167-187.

CERTEAU, Michel de. A invenção do cotidiano: 1. artes de fazer. Trad. Ephraim Ferreira Alves. Petrópolis: Vozes, 1994.

CHEN, Ying. Quatre mille marches. Montréal: Boréal, 2004.

DESROSIERS, Joël. Théories caraïbes: poétiques du déracinement. Essai. Montréal: Tryptique, 1996.

GALEANO, Eduardo. As palavras andantes. Trad. Eric Nepomuceno. Porto Alegre: L\&PM, 1994.

GAUVIN, Lise. Langagement: l'écrivain et la langue au Québec. Montréal: Boréal, 2000. GLISSANT, Édouard. Poétique de la relation. Paris: Gallimard, 1990.

GLISSANT, Édouard. Introduction à une poétique du divers. Paris: Gallimard, 1996.

HALL, Stuart. Da diáspora: identidades e mediações culturais. Trad. Adelaide Resende et al. Belo Horizonte: Ed. UFMG; Brasília: Representação da UNESCO no Brasil, 2003. HEIDEGGER, Martin. Essais et conférences. Trad. André Préau. Paris: Gallimard, 2010. 
HOTTE, Lucie; POIRIER, Guy (Dir.). Habiter la distance: études en marge de la distance habitée. Ottawa: Éditions Prise de Parole, 2009.

HUSTON, Nancy. Nord perdu; suivi de Douze France. Montréal: Leméac, 1999.

HUSTON, Nancy. Désirs et réalités: textes choisis 1978-1994. Montréal: Leméac/Actes Sud, 2001.

HUSTON, Nancy; SEBBAR, Leïla. Lettres parisiennes: autopsie de l'exil. Paris: Bernard Barrault, 1986.

LISBOA, Adriana. Rakushisha. Rio de Janeiro: Rocco, 2007.

MIZUBAYASHI, Akira. Une langue venue d'ailleurs. Paris: Gallimard, 2011.

MORENCY, Jean. Romanciers du Canada français. In: HOTTE, Lucie; POIRIER, Guy. Habiter la distance: études en marge de La distance habitée. Ottawa: Éditions Prise de Parole, 2009. p. 147-163.

OUELLET, Pierre. L'esprit migrateur: essai sur le non-sens commun. Montréal: VLB, 2005.

PARÉ, François. Les littératures de l'exigüité. Ottawa: Le Nordir, 1992.

PARÉ, François. La distance habitée. Essai. Ottawa: Le Nordir, 2003.

PARÉ, François. Le fantasme d'Escanaba. Montréal: Nota Bene, 2007.

PARÉ, François Postface: "Le fils éperdu". In: HOTTE, Lucie; POIRIER, Guy (Dir.). Habiter la distance: études en marge de La distance habitée. Ottawa: Éditions Prise de Parole, 2009. p. 183-189.

PORTO, Maria Bernadette. Escritas do exílio: habitar e representar a distância. In: PORTO, Maria Bernadette; VIANNA, NETO Arnaldo Rosa (Org.). Habitar e representar a distância em textos literários canadenses e brasileiros. Niterói: EdUFF, 2012. p. 15-34.

ROY, Gabrielle. La détresse et l'enchantement. Montréal: Boréal, 1984.

ROY, Gabrielle. De quoi t'ennuies-tu, Éveline? Suivi de Ély! Ély! Ély! Récits. Montréal: Boréal, 1988.

RUSHDIE, Salman. Patries imaginaires: essais et critiques 1981/1991. Paris: Christian Bourgois, 1993.

SEBBAR, Leïla. Je ne parle pas la langue de mon père. Récit. Paris: Éditions Julliard, 2003. SEBBAR, Leïla. L'arabe comme un chant secret. Récit. Paris: Bleu autour, 2007.

SIBONY, Daniel. Entre-deux: l'origine en partage. Paris: Seuil, 1991.

TREMBLAY, Michel. La grosse femme d'à côté est enceinte. Montréal: Leméac/Actes Sud, 1996. (Collection Babel)

TREMBLAY, Michel. La traversée du continent. Montréal: Leméac/Actes Sud, 2007.

TREMBLAY, Michel. La traversée de la ville. Montréal: Leméac/Actes Sud, 2008.

TREMBLAY, Michel. La traversée des sentiments. Montréal: Leméac/Actes Sud, 2009.

TREMBLAY, Michel. Le passage obligé. Montréal: Leméac / Actes Sud, 2010. 